\title{
Gestern war mehr Zukunft
}

Erhard Taverna

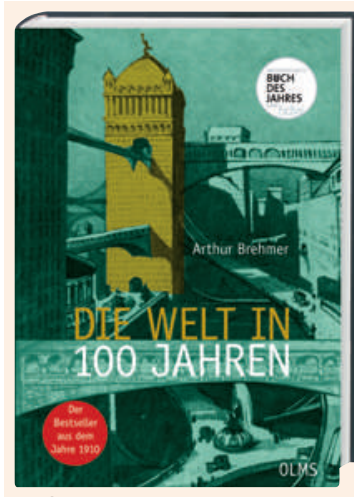

Arthur Bremer

Die Welt in 100 Jahren

8. Nachdruck der Ausgabe Berlin 1910

HIldesheim: Georg Olms

Verlag; 2010

319 Seiten, $12.30 \mathrm{CHF}$

ISBN 978-3-487-08304-9

erhard.taverna[at]saez.ch
Seriöse Futurologen betonen Qualitätskriterien wie logische Konsistenz, Überprüfbarkeit, Relevanz und Einfachheit der Modelle. Diesen lukrativen Markt der Zukunftsforschung teilen sich viele Anbieter, Grossbanken, Avenir Suisse, Swissfuture oder Zentren für Technologiefolgenabschätzung, wie TA-SWISS. Trendanalysen sollen wirtschaftliche und politische Entscheidungen erleichtern, die sich meist auf einen Zeithorizont von wenigen Jahren beschränken. Sie reichen von kurzfristigen Szenarien für Anleger bis zu den hochgerechneten Bevölkerungsstatistiken der nächsten Jahrzehnte. Berichte zu langsamen Veränderungen, etwa zu den Grenzen des Wachstums oder Klimaveränderungen, sind naturgemäss weniger präzise und umstrittener, da sie meist Verhaltensänderungen einfordern, die dem gewohnten Nutzendenken im Wege stehen. Voraussagen, die ein Jahrhundert oder mehr betreffen, sind Propheten oder ScienceFiction-Schreibern vorbehalten, eine Domäne der Spekulation und Fantasie.

Zum Wissenschaftsbuch des Jahres wurde 2010 ein Werk erkoren, das, ausser einer kurzen Einleitung,

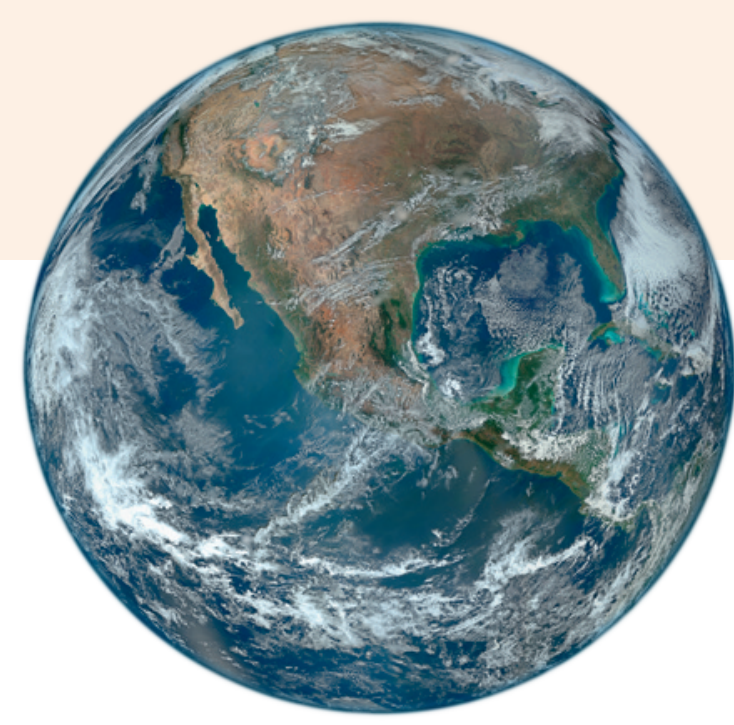

«Die kraftvolle Natur des neuen, gesunden Geschlechts trägt dazu bei, dass alle Operationen in kürzester Zeit ausheilen [...] Die Chirurgie wird künftighin nicht nur eine grandiose Wissenschaft sein, sondern auch ein Sport.» Den restlichen Organismus heilen desinfizierende Elektro-Osmosen. Auch Frauen, Mütter und die Liebe kommen nicht zu kurz, so wenig wie Umgangsformen und Städtebau. Fast alles ist vorstellbar, ausser dass das Hütetragen dereinst nicht mehr Mode sein könnte.

\section{Der Reiz der Lektüre besteht natürlich darin, dass wir diese Zukunft von gestern aus der Gegenwart beurteilen können.}

aus dem inzwischen 8. Nachdruck eines 1910 erschienenen Bestsellers besteht: «Die Welt in 100 Jahren», eine Anthologie von 22 Experten, darunter Cesare Lombroso über Verbrechen und Wahnsinn im 21. Jahrhundert und Bertha von Suttner zum Frieden in 100 Jahren. Der ausserordentliche Reiz der Lektüre besteht natürlich darin, dass wir diese Zukunft von gestern aus der Gegenwart beurteilen können. Das vom damals einflussreichen Journalisten Arthur Bremer (1858-1923) versammelte Kollektiv wagt neben technischen auch gesellschaftliche-politische Prognosen, die von Produktionsbedingungen, Energiegewinnung, Modewelten, Kolonien, Religion, Kunst und Emanzipation bis zum Weltuntergang reichen.

Aus heutiger Sicht am zutreffendsten sind die Vorstellungen einer weltumspannenden, drahtlosen Kommunikation, die mittels eines persönlichen Taschentelefons jedem zugänglich ist. Vom «Jahrhundert des Radiums» werden medizinische Wunder erwartet. Die Strahlen heilen Infekte und Tumoren, sie machen Blinde sehend und verzögern das Altern. Leibesübungen, Eugenik und eine saubere Umwelt machen den zukünftigen Organersatz zur Routine:
Zahlreiche Illustrationen führen vor Augen, wie selbst die kühnsten Visionen den Zeitumständen verhaftet bleiben. Uns Spätgeborenen ist der Fortschrittsoptimismus der Urgrosseltern fast nicht mehr nachvollziehbar. Noch leuchtet die Welt der Technik in den herrlichsten Farben. Auschwitz, Workuta, Hiroshima und Tschernobyl sind im tonangebenden Bürgertum des Fin de Siècle undenkbar. Zwar wird es in 100 Jahren noch einmal einen Krieg der VakuumLuftschiffe geben, doch im Jahre 2009 «ist die gelbe Rasse zur Erkenntnis gekommen, dass infolge der aeronautischen Überlegenheit der weissen Rasse, jeder Widerstand künftig vergeblich sei». Der materiellen Vollendung werde eine Ära der ethischen und philosophischen Vollendung und der Entwicklung einer höheren psychischen Kultur folgen. Niemand ahnt die nahe Katastrophe des Ersten Weltkrieges. Vom Illustrator des Bandes, Ernst Lübbert, heisst es im einführenden Essay von Georg Ruppelt nur kurz: «Fiel im August 1915 in Weissrussland bei einem Sturmangriff.»

Die digital vernetzte Welt ist komplexer geworden. Der technische Fortschrittsglaube wird heute, zumin- 
dest in Europa, von tiefempfundenen Ängsten überschattet. Autoritäten werden nicht mehr fraglos anerkannt, und nicht jeder traut den Megaprojekten der Wissenschaftseliten, denn allzu offensichtlich sind sie mit Ausbeutung, Macht, Geld und unbekannten Risiken kontaminiert. Unser Lebensstil könnte sich definitiv als ökologische Sackgasse herausstellen. Viele positive Indikatoren von damals, wie Bevölkerungswachstum und gestiegene Lebenserwartung, offenbaren ihre negativen Seiten. Angeblich unerschöpfliche Ressourcen sind endlich, die Selbstvernichtung ist machbar. Weit oben auf der Hitliste möglicher Katastrophen stehen neue Waffensysteme, Nanotechnologie, künstliche Intelligenz und die synthetische Biologie. Die belletristische Literatur ist damals wie heute aufschlussreicher, weil fantasievoller und intuitiver als die Gutachten von Sachverständigen. Die modernen Nachfahren vom Format eines Jules Verne, H.G. Wells oder einer Mary Shelley denken unabhängig und sind spannender zu lesen als der professionelle Computerausstoss bezahlter Denkfabriken und Thinktanks.

Vieles wird geschehen, was wir noch nicht wissen. Die Menschen von 1910 waren genauso klug, wie wir es heute sind. Ihre Voraussagen sind erfüllt von der Sehnsucht nach einem glücklichen Leben, getragen von Vernunft und Allgemeinsinn. Die überaus lesenswerte Lektüre mahnt zu Vorsicht und Bescheidenheit. 